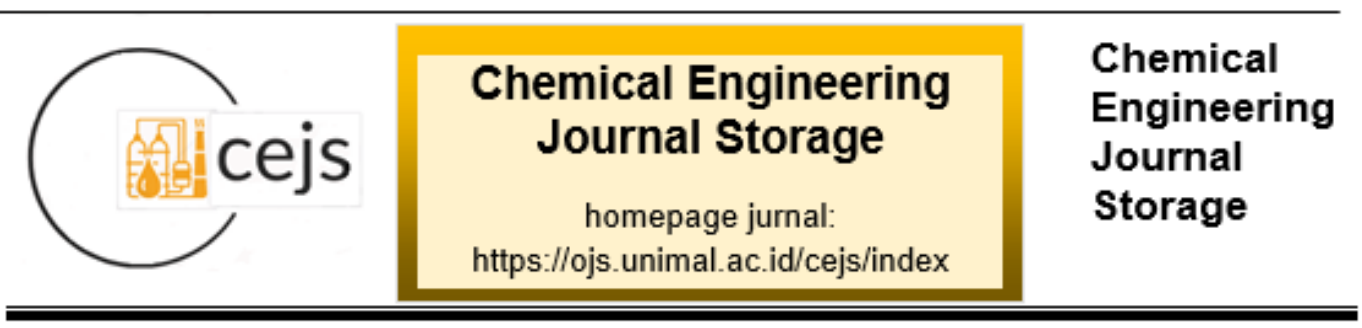

\title{
ANALISA PENGARUH JARAK ANTAR BAFFLE TERHADAP GETARAN PADA HEAT EXCHANGER TYPE SHELL AND TUBE DENGAN MENGGUNAKAN SOFTWARE HEAT TRANSFER RESEARCH INC (HTRI)
}

\author{
Nurrahmat Arif, Nasrul ZA, Azhari \\ Jurusan Teknik Kimia, Fakultas Teknik, Universitas Malikussaleh \\ Kampus Utama Cot Teungku Nie Reuleut, Muara Batu, Aceh Utara-24355 \\ Korespondensi:HP: 082164699680, e-mail: nasrulza@unimal.ac.id
}

\begin{abstract}
Abstrak
Heat Exchanger adalah suatu alat yang memungkinkan heat transfer dan dapat berfungsi baik sebagai pemanas maupun pendingin. Baffle merupakan sekatsekat pada Shell and Tube Heat Eexchanger (STHE) yang berfungsi untuk menciptakan aliran yang turbulen sehingga heat transfer yang terjadi optimal. Masalah yang terjadi STHE ini adalah getaran yang dapat merusak STHE maupun menyebabkan kegagalan pada heat exchanger. Penelitian ini bertujuan menganalisa pengaruh jarak baffle serta jenis baffle single segment dan double segment terhadap getaran yang terjadi guna menghindari kerusakan maupun kegagalan pada heat exchanger. Pelaksanaan penelitian ini dengan cara menyiapkan model STHE pada software heat transfer research inc (HTRI) dan memasukkan variasi nilai jarak baffle beserta jenis baffle single segment dan double segment, selanjutnya dilakukan analisa terhadap report data hasil dari software HTRI. Hasil analisa yang didapatkan jumlah baffle terbanyak pada jarak baffle $650 \mathrm{~mm}$ baik jenis single segment maupun double segment dengan jumlah baffle 17, getaran maksimum pada jarak baffle $650 \mathrm{~mm}$ baik single segment dan double segment dengan tube natural frequency $35,2 \mathrm{~Hz}$ dan heat transfer co-efficient analisa ini dengan jenis baffle single segment pada jarak $800 \mathrm{~mm}$ didapat heat transfer co-efficient $1221,8 \mathrm{Kcal} / \mathrm{m} 2 . \mathrm{hr} .{ }^{\circ} \mathrm{C}$, sedangkan pada jenis baffle double segment pada jarak $1000 \mathrm{~mm}$ dengan heat transfer coefficient 1188,6 Kcal/m2.hr. ${ }^{\circ}$.
\end{abstract}

Kata kunci: Baffle, Shell and tube heat exchanger (STHE), Single segment, Tube natural frequency

\section{Pendahuluan}

Suatu proses di dalam industri, kebutuhan memindahkan energi panas dari satu aliran ke aliran lain merupakan hal yang khas dilakukan, untuk itu penukar 
panas memegang peranan penting. Penukar panas shell-tube adalah jenis yang paling umum digunakan dalam industri. Jenis ini biasanya dilengkapi dengan baffle sehingga diperoleh aliran sisi shell dengan turbulensi yang tinggi.

Penukar panas atau heat exchanger adalah suatu alat yang memungkinkan perpindahan panas dan bisa berfungsi sebagai pemanas, pendingin maupun pengubah fasa. Penukar panas atau heat exchanger perlu dirancang mungkin agar heat transfer antar fluida berlangsung secara efisien. Masalah utama dalam analisa baffle terhadap getaran pada tube adalah jarak baffle itu sendiri maupun jenis baffle yang digunakan (Serth, 2007).

Getaran pada alat penukar panas ini diketahui memiliki dampak yang sangat merugikan. (Dharmeshkumar, 2008) efek getaran yang terjadi dalam alat penukar panas dapat menimbulkan suara yang menderu disekitar alat hingga radius $10-15 \mathrm{~m}$. Adapun cara untuk menganalisa getaran tersebut dapat menggunakan software Heat Transfer Research Inc (HTRI), Computational Fluid Dynamic (CFD), Ansys Fluent dan lainnya.

\section{Peralatan dan Metode}

Pelaratan yang digunakan pada penelitian berupa:

a. Satu buah laptop Acer, processor Amd E2-6110 APU, 64-Bit Operating System

b. Software Heat Transfer Research, Inc. (HTRI) Suite 7.3.2 Software pelengkap Microsoft Office dan Microsoft Excel

Pada penelitian ini terdapat beberapa tahapan yaitu:

a. Membuat model shell \& tube heat exchanger pada HTRI

b. Mengubah parameter jarak dan jenis baffle shell \& tube heat exchanger pada HTRI

c. Melakukan analisa jumlah baffle, getaran dan heat transfer co-efficient required

d. Menganalisa efek getaran terhadap jarak baffle 


\section{Hasil dan Diskusi}

\subsection{Analisa Jumlah Baffle, Getaran dan Overall Heat transfer Co-Efficient Required}

Pengujian terhadap jarak baffle dan jenis baffle dilakukan untuk mengetahui kinerja heat exchanger type shell and tube terhadap getaran yang terjadi pada heat exchanger type shell and tube di PT. Pupuk Iskandar Muda-2 menggunakan software heat transfer research inc (HTRI). Hasil analisa jarak baffle dan jenis baffle single segmental yang selanjutnya menjadi tinjauan dalam perancangan heat exchanger type shell and tube yang hasilnya ditunjukkan pada Tabel 3.1.

Table 3.1 Hasil Analisa Jumlah Baffle, Getaran dan Overall Heat transfer

CoEfficient Required (Ureq) pada Jenis Single segmental Baffle

\begin{tabular}{|c|c|c|c|c|c|}
\hline Run & $\begin{array}{c}\text { Baffle } \\
\text { Spacing } \\
(\mathrm{mm})\end{array}$ & Baffle Type & $\begin{array}{c}\text { Baffle } \\
\text { Quantity }\end{array}$ & $\begin{array}{c}\text { Tube Natural } \\
\text { frequency } \\
\text { (Hz) }\end{array}$ & $\begin{array}{c}\text { Heat transfer } \\
\text { Co-Efficient } \\
\left(\mathrm{Kcal} / \mathrm{m}^{2} . \mathrm{hr} .{ }^{\circ} \mathrm{C}\right)\end{array}$ \\
\hline 1. & 650 & \multirow{10}{*}{ Single Segment } & 17 & 35,2 & 1210,5 \\
\hline 2. & 700 & & 15 & 30,4 & 1220,3 \\
\hline 3. & 800 & & 14 & 23,3 & 1221,8 \\
\hline 4. & 900 & & 12 & 18,7 & 1211,7 \\
\hline 5. & 1000 & & 11 & 15,5 & 1207 \\
\hline 6. & 1100 & & 10 & 12,8 & 1202,9 \\
\hline 7. & 1200 & & 9 & 11 & 1191,4 \\
\hline 8. & 1300 & & 9 & 9,3 & 1193,7 \\
\hline 9. & 1400 & & 8 & 8,1 & 1188,7 \\
\hline 10. & 1500 & & 7 & 7,4 & 1183,9 \\
\hline
\end{tabular}

Sumber : Heat transfer research inc (HTRI)

Hasil analisa jarak baffle dan jenis baffle double segmental yang selanjutnya menjadi tinjauan dalam perancangan heat exchanger type shell and tube yang hasilnya ditunjukkan pada Tabel 3.2.

Table 3.2 Hasil Analisa Jumlah Baffle, Getaran dan Overall Heat transfer CoEfficient (U) pada Jenis Double segmental Baffle 


\begin{tabular}{|c|c|c|c|c|c|}
\hline Run & $\begin{array}{c}\text { Baffle } \\
\text { Spacing } \\
\text { (mm) }\end{array}$ & Baffle Type & $\begin{array}{c}\text { Baffle } \\
\text { Quantity }\end{array}$ & $\begin{array}{c}\text { Tube Natural } \\
\text { frequency } \\
\text { (Hz) }\end{array}$ & $\begin{array}{c}\text { Heat transfer } \\
\text { Co-Efficient } \\
\left(\mathrm{Kcal} / \mathrm{m}^{2} . \mathrm{hr} .{ }^{\circ} \mathrm{C}\right)\end{array}$ \\
\hline 1. & 650 & \multirow{10}{*}{ Double Segment } & 17 & 35,2 & 1187 \\
\hline 2. & 700 & & 15 & 30,4 & 1182,8 \\
\hline 3. & 800 & & 14 & 23,3 & 1183,5 \\
\hline 4. & 900 & & 12 & 18,7 & 1187,5 \\
\hline 5. & 1000 & & 11 & 15,2 & 1188,6 \\
\hline 6. & 1100 & & 10 & 12,8 & 1182,5 \\
\hline 7. & 1200 & & 9 & 10,7 & 1166 \\
\hline 8. & 1300 & & 9 & 9,2 & 1187,3 \\
\hline 9. & 1400 & & 8 & 8 & 1163,9 \\
\hline 10. & 1500 & & 7 & 7 & 1175,6 \\
\hline
\end{tabular}

Sumber : Heat transfer research inc (HTRI)

Masalah utama dalam mendesain heat exchanger merupakan getaran yang ditimbulkan dari alat heat exchanger itu sendiri yang salah satu penyebabnya yaitu akibat jarak baffle yang tidak sesuai dengan kondisi operasi sehingga menurunkan efektivitas dari alat heat exchanger itu sendiri (Serth, 2007).

Adapun jenis baffle yang divariasikan pada penelitian ini yaitu jenis baffle single segmental dan double segmental baffle. Variasi jenis baffle ini dilakukan guna menganalisa pengaruh terhadap getaran selain jarak baffle. Pemilihan jenis single segmental dikarenakan jenis tersebut merupakan jenis baffle standar dan umum digunakan dikarenakan distribusi aliran shell yang dihasilkan cukup baik (Serth, 2007). Sedangkan double segmental baffle merupakan jenis baffle yang memandu fluida pada sisi shell untuk mengalir dalam dua pola zigzag antara bundle tube. Intensitas turbulen pada double segmental baffle tidak setinggi pada single segmental baffle yang memiliki satu pola zigzag dan getaran yang diinduksi aliran cenderung lebih rendah (Ambekar et al., 2016).

Pada analisa getaran terhadap jarak baffle dan jenis baffle ini menggunakan software heat transfer research inc (HTRI). Lingkup cakupan HTRI ini mencakup 
design, rating dan simulasi baik dalam keperluan industri maupun alat-alat penukar panas lainnya seperti heat exchanger, penjepit rambut, boiler, evaporator dan kondensor. Dalam hal keperluan analisa HTRI ini menambilkan hasil kalkulasi pada report yang ditampilkan pada software HTRI tersebut (Halle et al., 1980).

Tube natural frequency merupakan frekuensi alami pada tube akibat induksi dari aliran yang melewati sisi tabung sehingga menyebabkan tabung berosilasi dan menyebabkan getaran disisi shell. Oleh karena itu, tube natural frequency merupakan hal utama yang perlu ditinjau dalam menganalisa getaran pada heat exchanger. Untuk mendapatkan getaran minimum perlu dianalisa jarak baffle dan jenis baffle dikarenakan baffle merupakan komponen pada heat exchanger tipe shell and tube yang berfungsi untuk menyangga/menahan tube untuk tidak berosilasi terlalu tinggi (U. H. Patel \& Bhojak, 2015).

Pengaruh jarak baffle dan jenis baffle terhadap getaran yang terjadi pada heat exchanger dimana heat exchanger dengan getaran tertentu menyebabkan timbulnya suara yang menderu akibat gesekan antar tube, terlepasnya tube dari tubesheet yang mengakibatkan kegagalan pada heat exchanger. Oleh karena itu, dalam memperoleh hasil getaran perlu dianalisa jarak-jarak baffle dengan batasan minimal didapat dari datasheet heat exchanger 127-C di PT. Pupuk Iskandar muda dan batasan maksimal hingga satu kali inside diameter shell. Dengan batasan variabel tetap panjang tube $12192 \mathrm{~mm}$ maka didapatkan dengan semakin besarnya jarak baffle maka semakin kecil jumlah baffle yang didapatkan.

\subsection{Baffle Spacing Terhadap Tube Natural Frequency}

Tube natural frequency merupakan frekuensi alami tube yang bergerak diakibatkan pola aliran dan kecepatan aliran. Adapun pengaruh jarak baffle terhadap tube natural frequency jenis single segmental baffle dapat dilihat dalam Gambar 3.1. 


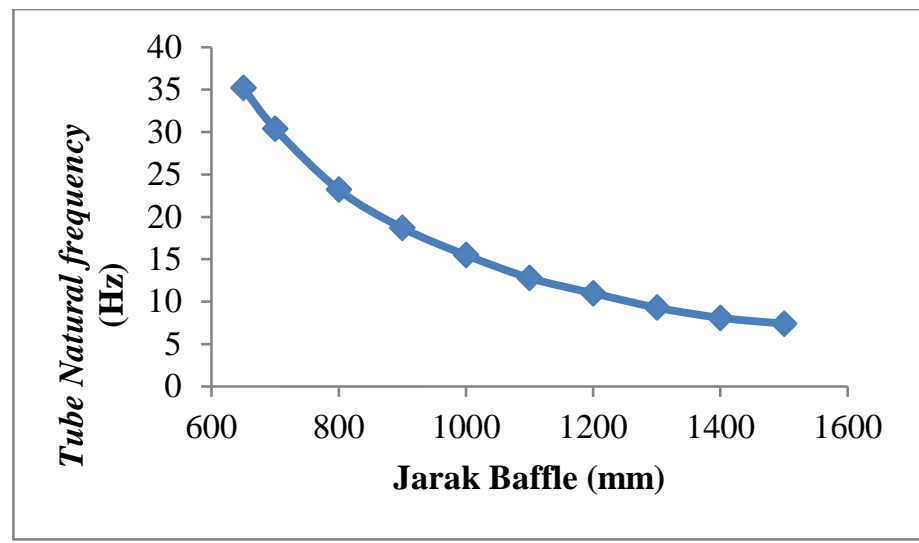

Gambar 3.1 Jarak baffle terhadap tube natural frequency

Dari data yang didapat berdasarkan analisa menggunakan aplikasi heat transfer research inc (HTRI) diperoleh hasil analisa yang terlampir pada gambar 3.1. Analisa jarak baffle terhadap tube natural frequency dengan jenis baffle single segmental didapatkan tube natural frequency tertinggi pada jarak baffle $650 \mathrm{~mm}$ dengan tube natural frequency $35,2 \mathrm{~Hz}$, sedangkan tube natural frequency terendah pada jarak $1500 \mathrm{~mm}$ dengan tube natural frequency 7,4 Hz. Pada jenis baffle single segmental dapat dilihat bahwa semakin tinggi jarak baffle maka tube natural frequency juga menurun. Pola getaran yang terjadi dengan posisi parallel cut baffle menimbulkan pola osilasi kekanan dan kekiri dikarenakan fluida ammonia yang melintasi bundle tube bergerak dengan sumbu X-Z lebih dominan dibandingkan dengan sumbu X-Y. Selanjutnya analisa tube natural frequency terhadap jarak baffle jenis double segmental seperti pada Gambar 3.2.

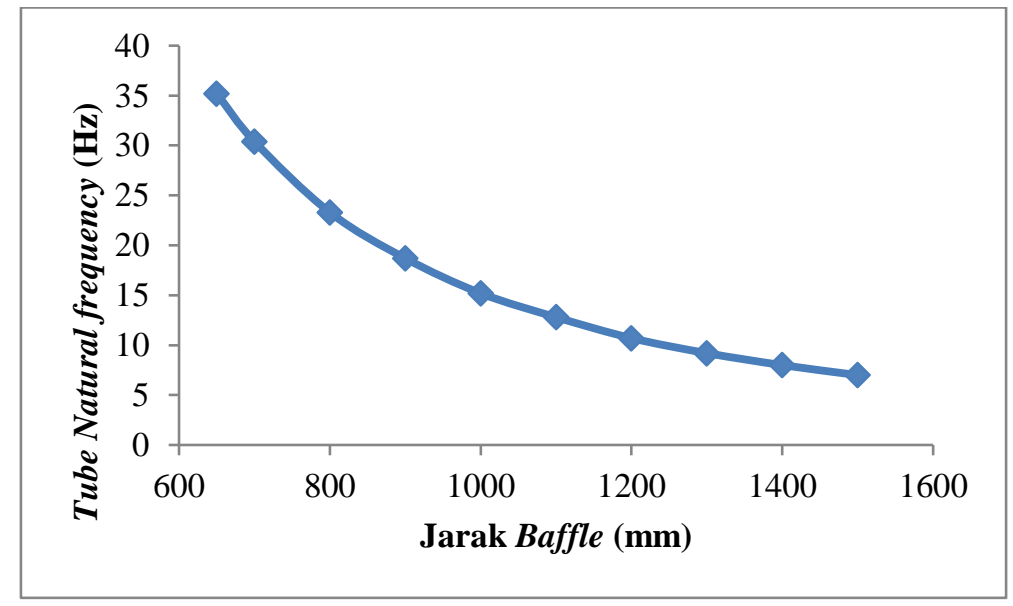

Gambar 3.2 Jarak baffle terhadap tube natural frequency 
Dari data yang didapat berdasarkan analisa menggunakan aplikasi heat transfer research inc (HTRI) diperoleh hasil analisa yang terlampir pada gambar 3.2. Analisa jarak baffle terhadap tube natural frequency dengan jenis baffle double segmental didapatkan tube natural frequency tertinggi pada jarak baffle $650 \mathrm{~mm}$ dengan tube natural frequency $35,2 \mathrm{~Hz}$, sedangkan tube natural frequency terendah pada jarak $1500 \mathrm{~mm}$ dengan tube natural frequency $7 \mathrm{~Hz}$. Pada jenis baffle single segmental dapat dilihat bahwa semakin tinggi jarak baffle maka tube natural frequency juga menurun.

Dari gambar 3.1 dan 3.2 dapat diketahui bahwa pada jenis baffle double segmental untuk tube natural frequency dalam jarak baffle 1200 mm, 1300 mm, $1400 \mathrm{~mm}, 1500 \mathrm{~mm}$ lebih kecil dari tube natural frequency pada jenis baffle single segmental. Hal ini disebabkan karena semakin tinggi jarak baffle maka kemungkinan fluida disisi sel untuk bergejolak dan kecepatan aliran yang ditimbulkan ketika melintasi tabung menurun (U. H. Patel \& Bhojak, 2015). Serta pola aliran yang ditimbulkan pada jenis baffle double segmental yaitu dua pola zigzag sehingga induksi yang ditimbulkan tidak seperti pola aliran pada jenis single segmental yang hanya satu pola zigzag (Ambekar et al., 2016). Nilai tube natural frequency terbesar yang didapat pada jarak baffle $650 \mathrm{~mm}$ dengan nilai tube natural frequency $35,2 \mathrm{~Hz}$ baik menggunakan jenis baffle single segmental maupun double segmental dianggap tidak merusak ataupun menimbulkan permasalahan pada heat exchanger type shell and tube dikarenakan jarak baffle tersebut merupakan jarak baffle design heat exchanger

Pernyataan ini didukung oleh penelitian yang dilakukan sebelumnya oleh (B. M. Patel, 2013) yang mendapatkan nilai tube natural frequency sebesar 292,4 Hz. Hal ini terjadi dikarenakan kurangnya penyangga tube sehingga ketika aliran fluida melintasi sisi tube terjadi osilasi yang mengakibatkan tube bergetar dan dapat mengakibatkan kerusakan yang fatal. Aliran sisi shell juga dapat menghasilkan gaya eksitasi yang menghasilkan getaran tube yang merusak. Kerentanan heat exchanger terhadap aliran getaran yang diinduksi aliran tergantung pada laju aliran, material tube dan baffle, bentang tube yang tidak didukung, tata letak bidang tube serta diameter shell (Byrne, 2007). 


\subsection{Baffle Spacing Terhadap Heat Transfer Co-Efficient Required}

Adapun pengaruh jarak baffle yang lainnya yaitu heat transfer co-efficient seperti yang dapat dilihat pada Gambar 3.3.

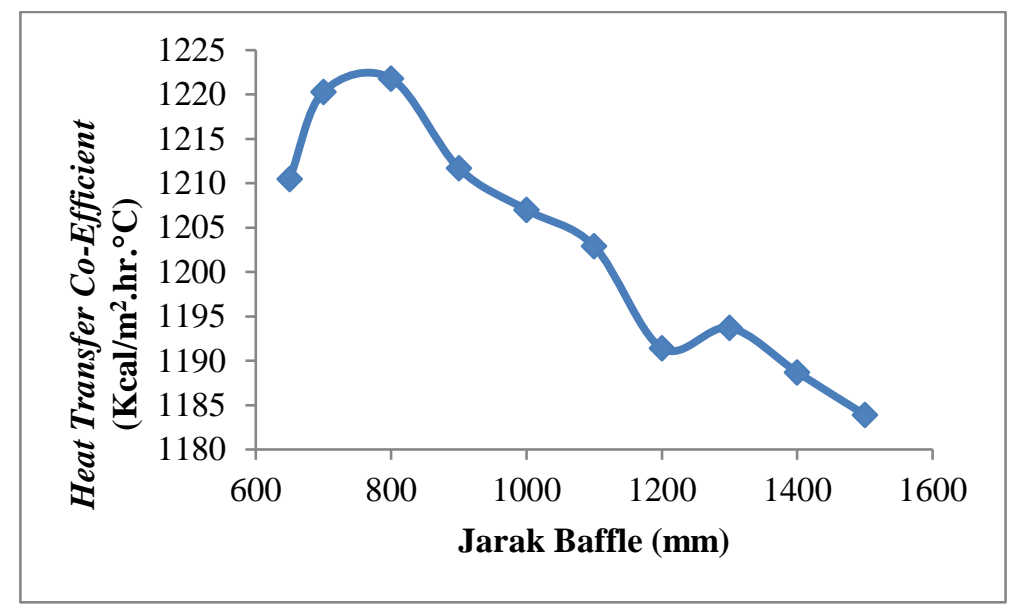

Gambar 3.3 Jarak baffle terhadap Heat transfer Co-Efficient (U)

Dari data yang didapat berdasarkan analisa menggunakan aplikasi heat transfer research inc (HTRI) diperoleh hasil analisa yang terlampir pada gambar 3.3. Analisa jarak baffle terhadap heat transfer co-efficient dengan jenis baffle single segmental didapatkan nilai heat transfer co-efficient yang didapatkan dari software heat transfer research inc (HTRI) tertinggi pada jarak baffle $800 \mathrm{~mm}$ sebesar $1221,8 \mathrm{Kcal} / \mathrm{m}^{2} . \mathrm{hr} .{ }^{\circ} \mathrm{C}$. Namun nilai heat transfer pada jarak $800 \mathrm{~mm}$ mencapai heat transfer yang optimum dengan mempertimbangkan getaran yang terjadi juga tidak mengganggu serta merusak sistem dari kinerja heat exchanger. Hal ini disebabkan karena semakin kecil jarak baffle maka transfer panas yang terjadi maksimum (Bangun et al., 2016). Selanjutnya dalam pemilihan jarak baffle 650mm pada heat exchanger type shell and tube 61-127-C di PT. Pupuk Iskandar Muda dianggap baik dengan nilai heat transfer $1210,5 \mathrm{Kcal} / \mathrm{m}^{2} . \mathrm{hr} .{ }^{\circ} \mathrm{C}$ (Engineering, 1999) yang tidak terpaut terlalu jauh dari nilai optimum di jarak baffle $800 \mathrm{~mm}$ dengan mempertimbangkan kondisi dinamis pada saat start up seperti perubahan laju alir, fouling rate pada fluida dan factor-faktor lainnya. Tingkat terbaik efektivitas heat transfer dalam heat exchanger terjadi pada aliran cross flow (Hewitt et al., 1994). Selanjutnya analisa heat transfer co-efficient terhadap jarak baffle jenis double segmental seperti pada Gambar 4.4. 


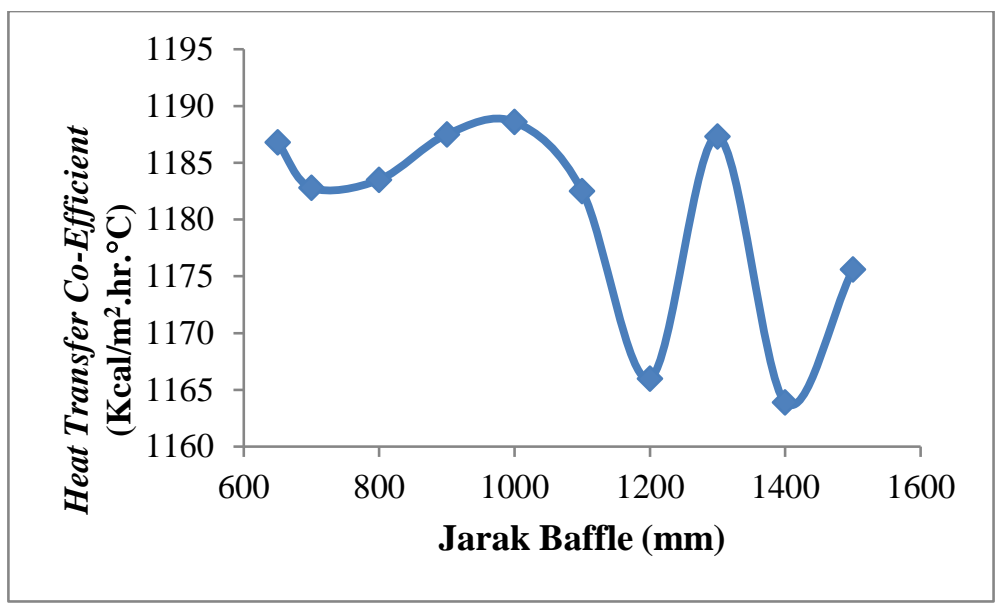

Gambar 3.4 Jarak baffle terhadap Heat transfer Co-Efficient (U)

Dari data yang didapat berdasarkan analisa menggunakan aplikasi heat transfer research inc (HTRI) diperoleh hasil analisa yang terlampir pada gambar 3.3. Analisa jarak baffle terhadap heat transfer co-efficient dengan jenis baffle single segmental didapatkan nilai heat transfer co-efficient yang didapatkan dari software heat transfer research inc (HTRI) tertinggi pada jarak baffle $1000 \mathrm{~mm}$ sebesar $1188,6 \mathrm{Kcal} / \mathrm{m}^{2} . \mathrm{hr} .{ }^{\circ} \mathrm{C}$. Namun nilai heat transfer co-efficient pada jenis baffle double segmental lebih tidak stabil berdasarkan jarak yang dianalisa diakibatkan tumpang tindihnya aliran yang melintasi baffle tidak secara bersamaan sehingga munculnya vortex shedding pada aliran disisi shell. Dari data analisa diatas dapat diketahui dengan menggunakan jenis baffle double segmental didapatkan nilai heat transfer terbaik dalam jarak baffle $1000 \mathrm{~mm}$ dengan heat transfer $1188,6 \mathrm{Kcal} / \mathrm{m}^{2} . \mathrm{hr} .{ }^{\circ} \mathrm{C}$. Namun, nilai heat transfer optimum pada jenis baffle single segmental lebih besar dibandingkan nilai optimum pada jenis baffle double segmental. Hal ini dikarenakan pada jenis baffle double segmental jumlah baris tube tumpang tindih sehingga aliran cross flow pada bundle tube kurang tercapai (Byrne, 2007). 


\section{Simpulan dan Saran}

Berdasarkan hasil penelitian dapat ditarik kesimpulan sebagai berikut:

1. Semakin besar jarak baffle maka semakin sedikit jumlah baffle baik dengan jenis baffle single segmental maupun double segmental.

2. Pola getaran yang terjadi kekanan dan kekiri dengan sumbu X-Z.

3. Tube natural frequency yang terjadi akibat gaya eksitasi yang ditimbulkan induksi aliran yang melintasi tube.

4. Getaran yang terjadi pada heat exchanger dapat diabaikan karena frequency terbesar hanya $35,2 \mathrm{~Hz}$.

5. Heat transfer co-efficient tertinggi pada jenis baffle single segmental pada jarak baffle $800 \mathrm{~mm}$ dan $1000 \mathrm{~mm}$ pada jenis baffle double segmental.

6. Keefektifan heat transfer sangat dipengaruhi oleh aliran cross flow pada bundle tube.

Berdasarkan hasil yang diperoleh pada penelitian ini, dapat disarankan pada penelitian selanjutnya perlu dilakukan analisa menggunakan computational fluid dynamic (CFD) untuk melihat dinamika getaran yang terjadi.

\section{Daftar Pustaka}

Ambekar, A. S., Sivakumar, R., Anantharaman, N., \& Vivekenandan, M. (2016). CFD simulation study of shell and tube heat exchangers with different baffle segment configurations. Applied Thermal Engineering, 108, 999-1007. https://doi.org/10.1016/j.applthermaleng.2016.08.013

Bangun, J. M., ZA, N., \& Azhari. (2016). Analisa Pengaruh Jarak Antar Baffle Terhadap Perpindahan Panas pada Alat Penukar Kalor Jenis Shell and Tube dengan Menggunakan Metode Simulasi Computational Fluid Dynamic (CFD). In Prosiding Seminar Nasional Teknik Kimia (p. 347).

Byrne, R. C. (2007). Standard of the Tubular Exchanger Manufacturers Association (9th ed.). http://www1.frm.utn.edu.ar/electromecanica/materias pagina nuevas/INSTALACIONES TERMICAS MECANICAS Y FRIGORIFICAS/material/apuntes/TEMA_9TH_EDITION_2007.pdf

Dharmeshkumar, P. (2008). Vibration Analysis Of Heat Exchanger Using CFD

[Sardar Vallabhbhai National Institute of Technology]. https://doi.org/10.1109/et2ecn.2012.6470056

Engineering, T. (1999). Equipment Data Sheet (Patent No. BA-0456). Toyo 
engineering Corporation.

Halle, H., Chenoweth, M., Wambsganss, M. W., \& Division, C. T. (1980). DOE/ANL/HTRI Heat Exchanger Tube Vibration Data Bank.

Hewitt, G. F., Shires, G. L., \& Bott, T. R. (1994). Process Heat Transfer. CRC Press.

Patel, B. M. (2013). Vibration Analysis of AES Type Shell and Tube Heat Exchanger By HTRI Software. International Journal of Advanced Engineering Research and Studies.

Patel, U. H., \& Bhojak, K. N. (2015). Design Optimization of Shell and Tube Heat Exchanger by Vibration Analysis through HTRI. International Journal of Modern Trends in Engineering and Research ( IJMTER ), 02(04), 115122.

Serth, W. R. (2007). Process Heat Transfer Principles and Applications. In Elsevier's Science \& Technology (First). 